\title{
In Vitro Stability of Free and Glucuronidated Cannabinoids in Urine Following Controlled Smoked Cannabis
}

\author{
Nathalie A. Desrosiers ${ }^{1,2}$, Dayong Lee ${ }^{1,2}$, Karl B. Scheidweiler $^{1}$, Marta Concheiro-Guisan ${ }^{1}$, \\ David A. Gorelick ${ }^{1}$, and Marilyn A. Huestis ${ }^{1}$ \\ ${ }^{1}$ Chemistry and Drug Metabolism Section, Clinical Pharmacology and Therapeutic Research \\ Branch, NIDA IRP, Baltimore, MD, USA \\ ${ }^{2}$ Program in Toxicology, University of Maryland Baltimore, Baltimore, MD, USA
}

\section{Abstract}

\begin{abstract}
Analyte stability is an important factor in urine test interpretation, yet cannabinoid stability data are limited. A comprehensive study of $\Delta^{9}$-tetrahydrocannabinol (THC), 11-hydroxy-THC (11-OHTHC), 11-nor-9-carboxy-THC (THCCOOH), cannabidiol, cannabinol, THC-glucuronide, and THCCOOH-glucuronide stabilities in authentic urine was completed.
\end{abstract}

Urine samples after ad libitum cannabis smoking were pooled to prepare low and high pools for each study participant; baseline concentrations were measured within $24 \mathrm{~h}$ at room temperature (RT), $4^{\circ} \mathrm{C}$ and $-20^{\circ} \mathrm{C}$. Stability at RT, $4^{\circ} \mathrm{C}$ and $-20^{\circ} \mathrm{C}$ was evaluated by Friedman tests for up to 1 year.

THCCOOH, THC-glucuronide, and THCCOOH-glucuronide were quantified in baseline pools. RT THCCOOH baseline concentrations were significantly higher than $-20^{\circ} \mathrm{C}$, but not $4^{\circ} \mathrm{C}$ baseline concentrations. After 1 week at RT, THCCOOH increased, THCCOOH-glucuronide decreased, but THC-glucuronide was unchanged. In RT low pool, total THCCOOH (THCCOOH $+\mathrm{THCCOOH}$-glucuronide) was significantly lower after 1 week. At $4^{\circ} \mathrm{C}$, THCCOOH was stable 2 weeks, THCCOOH-glucuronide 1 month and THC-glucuronide for at least 6 months. THCCOOH was stable frozen for 1 year, but 6 months high pool results were significantly higher than baseline; THC-glucuronide and THCCOOH-glucuronide were stable for 6 months. Total THCCOOH was stable 6 months at $4^{\circ} \mathrm{C}$, and frozen 6 months (low) and 1 year (high). THC, cannabidiol and cannabinol were never detected in urine; although not detected initially, 11-OHTHC was detected in 2 low and 3 high pools after one week at RT.

Substantial THCCOOH-glucuronide deconjugation was observed at RT and $4^{\circ} \mathrm{C}$. Analysis should be conducted within 3 months if non-hydrolyzed THCCOOH or THCCOOH-glucuronide quantification is required.

\section{Keywords \\ Cannabinoids; urine; stability; glucuronide}

Corresponding Author, Professor Dr. Dr. (h.c.) Marilyn A. Huestis, Chief, Chemistry and Drug Metabolism, Intramural Research Program, National Institute on Drug Abuse, National Institutes of Health, 251 Bayview Boulevard, Suite 200 Room 05A-721, Baltimore, MD 21224, Tel: 1-443-740-2524, Fax: 1-443-740-2823, mhuestis@ intra.nida.nih.gov. 


\section{Introduction}

Cannabis is the most commonly abused illicit drug worldwide, with 2.6-5.0\% (119-224

million people) aged 15-64 consuming cannabis at least once in 2010 [1]. In 2011, 872,000

Americans sought treatment for cannabis dependence or abuse, second only to alcohol [2].

$\Delta 9$-tetrahydrocannabinol (THC), the main active compound in cannabis, was the most prevalent illicit drug detected in injured drivers in Victoria, Australia (9.8\%) [3] and cannabinoids were identified in blood and/or oral fluid in $8.6 \%$ of nighttime drivers in the 2007 US Roadside Survey [4].

Given the high prevalence of cannabis use and of urine testing for cannabis in many contexts, it is critical to accurately interpret a positive urine test. THC is rapidly metabolized to 11-hydroxy-THC (11-OH-THC) and 11-nor-9-carboxy-THC (THCCOOH), with these primarily present as phase II glucuronide conjugates, and perhaps to a minor extent, as sulfates [5]. THC, 11-OH-THC and THCCOOH are conjugated through UDPglucuronosyltransferase (UGT); THC is glucuronidated on the phenolic alcohol, forming an ether glucuronide, whereas $\mathrm{THCCOOH}$ glucuronidation produces an ester glucuronide [5]. 11-OH-THC can form ether glucuronides on either the phenolic or the 11-hydroxyl groups. 11-OH-THC and THCCOOH diglucuronidation could occur, but is unlikely due to steric hindrance.

Recent research documented urinary $\mathrm{THC}$ and $\mathrm{THCCOOH}$ extended detection windows in chronic frequent smokers following tandem enzyme and alkaline hydrolysis [6-7]. New models were suggested to identify recent or new cannabis use in occasional [8] and chronic frequent cannabis smokers [9]. There also were proposals to monitor unconjugated THCCOOH [10-11], $\Delta^{9}$-tetrahydrocannabinolic acid A [12], and THC-glucuronide [13], although these still need further research and validation. However, understanding cannabinoid stability is required to adequately interpret drug concentrations and apply these models or markers of recent use, especially if repeat analysis is requested months after initial testing. Urine cannabinoid adsorptive losses [14-17] and instability [18-20] are well documented. However, some studies utilized radioisotopes or immunoassay [14-15,19] and few studies utilized authentic urine samples or examined THCCOOH and THCCOOHglucuronide stability. Skopp and Pötsch originally documented time- and temperaturedependent $\mathrm{THCCOOH}$-glucuronide cleavage to $\mathrm{THCCOOH}$ in $\mathrm{THCCOOH}$-glucuronidefortified urine [21] and in authentic samples [22]. THCCOOH-glucuronide concentrations were stable for at least 15 days at $-20^{\circ} \mathrm{C}$ in authentic samples, but decreased at higher temperatures. In fortified samples, molar sums of THCCOOH-glucuronide and $\mathrm{THCCOOH}$ were equal to initial THCCOOH-glucuronide concentrations at $4{ }^{\circ} \mathrm{C}$, but not 20 or $40^{\circ} \mathrm{C}$. Furthermore, in fortified urine, higher $\mathrm{pH}$ increased $\mathrm{THCCOOH}$-glucuronide degradation, and $\mathrm{pH}$ increased over time [22]. These studies only investigated short-term cannabinoid stability, providing no long-term stability data that is required for initial analysis that may be delayed or repeat analyses months after initial testing. Felli et al. documented THCCOOH and $\mathrm{THCCOOH}$-glucuronide stability for at least 7 and 120 days at 4 and $-20^{\circ} \mathrm{C}$ in 10 authentic urine samples, but did not describe changes in concentration [23]. Only one study 
documented analysis of THC-glucuronide; however, stability was not rigorously investigated [13].

We evaluated THC, 11-OH-THC, THCCOOH, cannabidiol (CBD), cannabinol (CBN), THC-glucuronide, and THCCOOH-glucuronide stability in 16 different low and high concentration urine pools collected from 16 participants after controlled cannabis smoking. These cannabinoid stability data generated from authentic samples will aid in interpreting urinary cannabinoid results.

\section{Methods}

\section{Participants}

Healthy males and females provided written informed consent to participate in this National Institute on Drug Abuse Intramural Research Program Institutional Review Board-approved study. Individuals were recruited by television, radio and newspaper advertisements, flyers, and referrals. Participants received a comprehensive medical and psychological evaluation to verify study eligibility. Inclusion criteria were ages 18 to 45 years and self-reported average frequency of smoked cannabis of less than twice per week (occasional smoker) or at least four times per week (chronic, frequent smoker) in the past 3 months. History of cannabis use was confirmed for chronic, frequent smokers by a positive urine cannabinoid test. Exclusion criteria included: breastfeeding or pregnant women; current medical condition or history of neurological illness; history of a clinically significant adverse event associated with cannabis intoxication; donation of $>450 \mathrm{~mL}$ blood within 30 days of drug administration; presence of clinically significant anemia; increased systolic or diastolic blood pressure or heart rate $>100 \mathrm{bpm}$ after $5 \mathrm{~min}$ rest; clinically significant electrocardiogram abnormality; or interest in drug abuse treatment within 60 days of study screening. Pregnancy tests were administered at screening and on study admission to women with reproductive potential.

\section{Study Design}

Participants entered the secure research unit approximately $19 \mathrm{~h}$ prior to cannabis dosing to preclude intoxication at the time of drug administration. Participants smoked one cannabis cigarette containing (mean \pm standard deviation) $6.8 \pm 0.2 \%$ (54 mg) THC, $0.25 \pm 0.08 \% \mathrm{CBD}$, and $0.21 \pm 0.02 \% \mathrm{CBN}$, ad libitum for up to $10 \mathrm{~min}$. Urine was collected ad libitum from admission up to $30 \mathrm{~h}$ after cannabis smoking. Urine was collected into $250 \mathrm{~mL}$ polypropylene bottles (Thomas Scientific, Swedesboro, NJ) and immediately refrigerated. Low and high concentration pools were prepared for each individual. All urine samples collected between 0 and $6 \mathrm{~h}$ post-dose were pooled in equal portions within $6 \mathrm{~h}$ of collection to form the high pool; low pool consisted of high pool diluted 1:5 (v/v) with fresh drug-free urine from a healthy volunteer. Urine $(3.5 \mathrm{~mL})$ was aliquoted into $3.6 \mathrm{~mL}$ round bottom polypropylene Nunc cryotubes (Thomas Scientific, Swedesboro, NJ) and stored in the dark. Baseline concentrations were obtained in triplicate within $24 \mathrm{~h}$ of collection from samples stored at room temperature (RT), $4^{\circ} \mathrm{C}$, and $-20^{\circ} \mathrm{C}$. Stability was evaluated in duplicates after 8 days at RT, 8,16 (range \pm 1 day), 30 ( $30 \pm 1$ days), 90 (93 \pm 5 days), and 180 (183 \pm 10 days) 
days at $4{ }^{\circ} \mathrm{C}$ and $-20^{\circ} \mathrm{C}$; and 1 year $\left(365 \pm 20\right.$ days) at $-20^{\circ} \mathrm{C}$. All sample concentrations were compared to their temperature-matched baseline samples.

\section{Urine Analysis}

Urine samples were analyzed for THC, 11-OH-THC, THCCOOH, CBD, CBN, THCglucuronide, and THCCOOH-glucuronide according to a previously published method [24]. Briefly, $0.5 \mathrm{~mL}$ urine was diluted with $0.2 \mathrm{M}$ ammonium acetate and $0.025 \mathrm{M}$ dibutylammonium acetate buffer solution, $\mathrm{pH} 6.3$ before transferring onto Isolute SLE+ columns (Biotage, Inc., Charlotte, NC). After 5 min equilibration, analytes were eluted with $5 \mathrm{~mL}$ ethyl acetate, dried and reconstituted in $150 \mu \mathrm{L}$ mobile phase, and injected onto the liquid chromatography tandem mass spectrometry (LC-MS/MS) instrument. Linear ranges were $2-100 \mu \mathrm{g} / \mathrm{L}$ for THC and CBN, $1-100 \mu \mathrm{g} / \mathrm{L}$ for $11-\mathrm{OH}-\mathrm{THC}$ and CBD, $1-250 \mu \mathrm{g} / \mathrm{L}$ for THCCOOH, $0.5-50 \mu \mathrm{g} / \mathrm{L}$ for THC-glucuronide, and 5-500 $\mu \mathrm{g} / \mathrm{L}$ for THCCOOHglucuronide. Interassay $(\mathrm{N}=50)$ analytical bias and imprecision were $92.2-102.16 \%$ and $5.2-$ $10.2 \%$, respectively. Urine creatinine was measured on a Roche/Hitachi Modular D2400 Analyzer by colorimetric assay based on the Jaffe reaction.

\section{Statistical Analysis}

Because data were non-normally distributed, statistical comparisons were conducted with nonparametric tests in Prism 5.02 (GraphPad Software, La Jolla, CA). Concentration decreases below the limit of quantification (LOQ) were represented as 0 in statistical comparisons but as $1 / 2 \mathrm{LOQ}$ for figures and $\%$ decrease calculations. Repeated-measures Friedman tests were used to evaluate differences between baseline concentrations and to compare cannabinoid concentrations, total THCCOOH (molar sums of free THCCOOH $+\mathrm{THCCOOH}$-glucuronide), and $\mathrm{pH}$ at different storage durations and temperatures to those at baseline. Dunn's multiple comparisons tests were employed for post hoc comparisons. Wilcoxon matched pairs test was employed to compare one week RT concentrations and $\mathrm{pH}$ to those at baseline. Generalized linear mixed model with sequential Bonferroni correction for multiple comparisons in SPSS 20.0 for Windows (IBM, Armonk, NY) evaluated the effects of initial $\mathrm{pH}$, initial $\mathrm{pH} \times$ change in $\mathrm{pH}$, and creatinine concentration on logtransformed cannabinoid concentrations. Results with 2-tailed $p<0.05$ were considered significant.

\section{Results}

\section{Human Participants}

Sixteen healthy cannabis smokers (12 males, 4 females), ages 19-37, participated in the study (Table 1). Participants reported smoking cannabis for mean \pm SD 10.5 \pm 3.6 years and consumed 5.6 \pm 6.4 joints or joint-equivalents (empirically-normalized joint consumption, to account for different smoking methods [i.e. bowl, pipe, blunt]) per day.

\section{Urinary Cannabinoid Stability}

Baseline urinary cannabinoid concentrations are shown in Fig 1. THCCOOH, THC-

glucuronide, and $\mathrm{THCCOOH}$-glucuronide were quantified at baseline in 12, 16, and $15 \mathrm{low}$ RT pools; 13, 16, and 15 high RT pools; 7, 16, and 15 low $4^{\circ} \mathrm{C}$ pools; 12, 16, and 15 high 
$4^{\circ} \mathrm{C}$ pools; 5,15 , and 15 low $-20^{\circ} \mathrm{C}$ pools; and 12,16 , and 15 high $-20^{\circ} \mathrm{C}$ pools, respectively. Total THCCOOH (molar sum of THCCOOH and THCCOOH-glucuronide) was measurable in 15 participants' low and high baseline pools. No baseline pool contained measurable THC, 11-OH-THC, cannabidiol, or cannabinol.

Baseline THCCOOH, THC-glucuronide, THCCOOH-glucuronide, and total THCCOOH concentrations were significantly pool and temperature dependent $\left(\chi^{2}(5)=56.6,65.3,59.1\right.$, and 62.1, respectively). Post hoc tests revealed that baseline concentrations were similar between storage temperatures, except for THCCOOH concentrations, which were significantly higher at $\mathrm{RT}$ compared to $-20^{\circ} \mathrm{C}$ high pools.

Median and range urinary cannabinoid stability results are shown in Fig 2. After one week at RT, THCCOOH concentrations significantly increased in both low and high pools (W=-120 for both low and high pools). At $4{ }^{\circ} \mathrm{C}$, THCCOOH concentrations significantly increased after 4 weeks in low and high pools $\left(\chi^{2}(5)=71.9\right.$ and 73.9). At $-20^{\circ} \mathrm{C}$, THCCOOH was stable for at least 52 weeks in the low pool $\left(\chi^{2}(6)=7.9\right)$, but increased in the high pool $\left(\chi^{2}\right.$ $(6)=14.1)$; post hoc analysis revealed that concentrations increased compared to baseline after 6 months, but not after 1 year. THCCOOH stability showed high inter-subject variability due to low concentrations. THCCOOH baseline-negative pools contained 1.6-5.6 and 3.2-18.4 $\mu \mathrm{g} / \mathrm{L}$ THCCOOH after one week at RT for low and high pools respectively; we did not detect THCCOOH increases for participant $\mathrm{O}$ whose initial pool contained $<5 \mu \mathrm{g} / \mathrm{L}$ THCCOOH-glucuronide. THCCOOH increased after two weeks at $4^{\circ} \mathrm{C}$ in all but one baseline-negative participant pools (Participant O), increasing up to 32.2 and $26.7 \mu \mathrm{g} / \mathrm{L}$ after six months in low and high pools, respectively. At $-20^{\circ} \mathrm{C}$, THCCOOH increases in baselinenegative pools were due to analytical variability in concentrations near the LOQ in low pools.

THC-glucuronide was stable for at least one week at RT ( $\mathrm{W}=70.0$ and -36.0 in low and high pools, respectively). We observed overall instability $\left(\chi^{2}(5)=14.93\right)$ in low pool at $4{ }^{\circ} \mathrm{C}$, although post hoc comparisons did not reveal any time points significantly differing from baseline. THC-glucuronide high pools were stable for at least 6 months $\left(\chi^{2}(5)=5.5\right)$. At $-20^{\circ} \mathrm{C}$, THC-glucuronide was stable for up to 6 months $\left(\chi^{2}(6)=36.1\right.$ and 38.6 in low and high pools, respectively), although high inter-subject variability was documented due to the low concentrations.

THCCOOH-glucuronide significantly decreased $(-26.2$ to $-95.2 \%$ in low pools and -21.2 to $-93.9 \%$ in high pools) after one week at RT (W=120 in low and high pools). After one week at RT, two low pools and one high pool were $<\mathrm{LOQ}$ (initial concentrations $5.4-52.4 \mu \mathrm{g} / \mathrm{L}$ ). Significant decreases were observed beyond 1 month at $4^{\circ} \mathrm{C}\left(\chi^{2}(5)=50.4\right.$ and 61.5 in low and high pools, respectively). Two low pools were $<\mathrm{LOQ}$ after 1 month and 6 months (baseline concentrations of 6.5 and $46.2 \mu \mathrm{g} / \mathrm{L}$, respectively). In high pools, 2 and 3 pools were <LOQ after 3 and 6 months, respectively (baseline concentrations ranges of 26.8-38.2 and $67.5-118 \mu \mathrm{g} / \mathrm{L}$, respectively). At $-20^{\circ} \mathrm{C}$, THCCOOH-glucuronide significantly decreased after 1 year $\left(\chi^{2}(6)=28.4\right.$ and 37.5 in low and high pools, respectively). 
Total THCCOOH concentrations significantly decreased in low pool after one week at RT $(\mathrm{W}=100)$, but not in high pool $(\mathrm{W}=68.0, \mathrm{P}=0.0554)$. At $4^{\circ} \mathrm{C}$, total THCCOOH concentrations significantly decreased overall $\left(\chi^{2}(5)=21.9\right.$ and 13.9 in low and high pools, respectively), although individual time points did not significantly differ from baseline. At $-20^{\circ} \mathrm{C}$, total $\mathrm{THCCOOH}$ concentrations decreased significantly over time $\left(\chi^{2}(6)=28.7\right.$ and 36.7 in low and high pools, respectively). Post hoc tests indicated 1-year concentrations were significantly lower than baseline in low pools, but no time points significantly differed from baseline in the high pools. The largest \% change occurred in participant $\mathrm{N}$ due to low THCCOOH and THCCOOH-glucuronide associated with occasional cannabis consumption.

THC, 11-OH-THC, CBD, and CBN were never detected in baseline samples. However, after one week at RT, 11-OH-THC appeared in 2 low and 3 high pools. Participant D had 1.4 $\mu \mathrm{g} / \mathrm{L}$ in one low pool replicate, participant $\mathrm{G}$ had 1.1 and $1.9 \mu \mathrm{g} / \mathrm{L}$ in low pool replicates, participant $\mathrm{C}$ had $1.7 \mu \mathrm{g} / \mathrm{L}$ in one high pool replicate, participant $\mathrm{G}$ had $1.7 \mu \mathrm{g} / \mathrm{L}$ in both high pool replicates and participant $\mathrm{J}$ had 6.3 and $7.9 \mu \mathrm{g} / \mathrm{L}$ in the high pool replicates. No samples stored at $4^{\circ} \mathrm{C}$ or $-20^{\circ} \mathrm{C}$ had detectable $11-\mathrm{OH}-\mathrm{THC}$ after 6 months or 1 year, respectively.

No THC, CBD or CBN were ever detected throughout the study.

\section{Effect of pH and Creatinine Concentration}

Urinary pH significantly increased over time (Fig 3); after one week at RT median (range) $\mathrm{pH}$ increases were $0.35(-0.32-3.85)(\mathrm{W}=120$ and -124.0 in low and high pools respectively). After six months at $4^{\circ} \mathrm{C}$, median increase was $0.44(0.02-1.36) \mathrm{pH}$ units $\left(\chi^{2}\right.$ (5) $=57.2$ and 65.2 in low and high pools, respectively). Post hoc tests revealed $\mathrm{pH}$ increased significantly after 2 weeks at $4{ }^{\circ} \mathrm{C}$ in both low and high pools. At $-20^{\circ} \mathrm{C}, \mathrm{pH}$ increased 0.35 $(-0.10-1.38)$ after 1 year $\left(\chi^{2}(5)=71.8\right.$ and 63.1 in low and high pools, respectively). Post hoc tests indicated that $\mathrm{pH}$ was significantly higher than baseline after 1 month and 2 weeks in low and high pools, respectively.

Because $\mathrm{pH}$ significantly increased over time, the effects of the initial $\mathrm{pH}$ and the interaction between initial $\mathrm{pH}$ and change in $\mathrm{pH}$ (initial $\mathrm{pH} \times$ change in $\mathrm{pH}$ ) on final cannabinoid concentrations were evaluated. Initial $\mathrm{pH} \times$ change in $\mathrm{pH}$ was a main effect on THCCOOH $(\mathrm{t}=23.5, \mathrm{p}<0.001)$; initial $\mathrm{pH}$ and initial $\mathrm{pH} \times$ change in $\mathrm{pH}$ were a main effect on THCglucuronide $(\mathrm{t}=2.9, \mathrm{p}<0.01$ and $\mathrm{t}=-3.4, \mathrm{p}<0.01)$, THCCOOH-glucuronide $(\mathrm{t}=2.9, \mathrm{p}<0.05$ and $\mathrm{t}=-25.2, \mathrm{p}<0.001)$, and total THCCOOH concentrations $(\mathrm{t}=3.0, \mathrm{p}<0.01$ and $\mathrm{t}=-9.3$, $\mathrm{p}<0.001)$. Creatinine concentrations did not affect THCCOOH, THC-glucuronide, THCCOOH-glucuronide, or total THCCOOH concentrations $(\mathrm{t}=1.6,0.9,0.1$, and 0.5, respectively).

\section{Discussion}

To our knowledge, this is the most comprehensive study examining in-vitro phase I and II urinary cannabinoids following extended storage after controlled smoked cannabis. In this study, we utilized polypropylene tubes for storage, even though adsorptive loss is less with glass tubes $[15,17]$. However, for safety reasons, plastic tubes are preferred for the storage of biological samples. Therefore, we utilized polypropylene tubes, which adsorb cannabinoids to a lesser extent than polyethylene tubes [15]. We aliquoted $3.5 \mathrm{~mL}$ urine into 
each $3.6 \mathrm{~mL}$ tube to reduce the surface area to volume ratio and minimize adsorptive losses. Previous research showed that adsorptive losses occur within $0.2-2 \mathrm{~h}$ after addition of solution or urine to a container, and that this loss plateaus [16, 15, 14]. Because our baselines were quantified within $24 \mathrm{~h}$, adsorptive loss may have already occurred; therefore, our measurements could be more reflective of analyte stability rather than changes in concentration due to adsorptive losses.

Previous long term stability studies utilized alkaline-hydrolyzed urine to monitor total THCCOOH $[18,20]$. However, direct and simultaneous analysis of THCCOOH and THCCOOH-glucuronide is preferred, as quantification following hydrolysis is more variable and it is difficult to ensure complete hydrolysis. Furthermore, previous studies documented reanalysis of case samples which underwent prior screening, as well as possible transport to the laboratory prior to initial analysis. Given that degradation of THCCOOH-glucuronide occurs in a first-order kinetic manner [21], degradation could have occurred before the initial analysis. In our study, we documented baseline concentrations (at three temperatures) within $24 \mathrm{~h}$ of collection from samples that were stored at $4^{\circ} \mathrm{C}$ for less than $6 \mathrm{~h}$ prior to making pools, minimizing any degradation that may have occurred between collection and initial analysis.

THCCOOH concentrations in high RT-stored baseline pools were significantly higher than frozen baseline pools. Previous work demonstrated that THCCOOH-glucuronide is labile and prone to deconjugation [21, 25, 22]. THCCOOH-glucuronide is mainly found as an ester-glucuronide; acyl and ester glucuronides are prone to deconjugation as well as intramolecular rearrangement by acyl group migration [26-27]. Therefore, the increase in $\mathrm{THCCOOH}$ is due to THCCOOH-glucuronide deconjugation. Although the increased THCCOOH derived from THCCOOH-glucuronide deconjugation, THCCOOH-glucuronide baseline concentrations at RT were not significantly lower than frozen baseline pools, due to the much higher THCCOOH-glucuronide concentrations yielding a lower percent change.

Skopp et al. previously reported time and temperature dependent conversion of THCCOOHglucuronide to THCCOOH in authentic urine samples [22]. At $4{ }^{\circ} \mathrm{C}$, THCCOOH-

glucuronide concentration decreases exceeded $25 \%$ in $7.9 \%$ and $13.2 \%$ of samples after 2 and 5 days, respectively. THCCOOH concentration increases ranged from 1-99\% in $21.1 \%$ and $28.9 \%$ of samples after 2 and 5 days, respectively; increases ranged from 100-499\% in $2.6 \%$ of samples after 5 days. At $20^{\circ} \mathrm{C}$, THCCOOH-glucuronide decreases exceeded $25 \%$ in $28.9 \%$ and $50 \%$ of samples after 2 and 5 days, respectively; THCCOOH increases exceeded $100 \%$ in 21.1 and $28.9 \%$ after 2 and 5 days, respectively. In our study, we also noted a time and temperature dependent conversion of THCCOOH-glucuronide to THCCOOH. After one week at RT, we saw complete degradation of THCCOOH-glucuronide in some participants' urine samples and $\mathrm{THCCOOH}$ increases up to $1346 \%$ of baseline. At $4{ }^{\circ} \mathrm{C}$, significant increases in THCCOOH (up to $1206 \%$ of baseline) occurred after 1 month; significant decreases in THCCOOH-glucuronide occurred after 3 months. At $-20^{\circ} \mathrm{C}$, THCCOOH concentration increases were significant in high pool after 6 months, but were not significant at 1 year; variability was larger after one year, likely confounding statistical findings (Fig 2). 
Skopp et al. also reported decreased total $\mathrm{THCCOOH}$ at $20^{\circ} \mathrm{C}$. Others also reported a trend towards decreased THCCOOH in authentic hydrolyzed urine [20,18]. We observed significant overall decreases in total THCCOOH in low pools after 1 week at RT and in low and high pools at 4 and $-20^{\circ} \mathrm{C}$, although post-hoc tests revealed that only samples stored for 1 year at $-20^{\circ} \mathrm{C}$ were significantly lower than baseline. It is unclear why total THCCOOH concentrations were unstable, although altered adsorption, intramolecular acyl migration, protein binding, or further molecular degradation could explain these changes. Early synthesis of cannabinoid metabolites used microbial transformation to produce certain metabolites on the pentyl side chain [28]. Skopp et al. proposed that microbial degradation of the side chain may be responsible for cannabinoid degradation.

THC-glucuronide concentrations significantly decreased only after one year at $-20^{\circ} \mathrm{C}$. High variability was documented in low pools, because concentrations were near the LOQ. Deconjugation of THC-glucuronide is not likely, as THC was not detected. Possible explanations for THC-glucuronide decreases include adsorption, protein binding or molecular degradation.

High inter-subject variability occurred for all analytes (Fig 2). This is most likely due to differences in $\mathrm{pH}$. The effect of higher $\mathrm{pH}$ on THCCOOH-glucuronide stability was previously documented [22]. In this study, we documented similar effects of initial urinary $\mathrm{pH}$, but also of initial $\mathrm{pH} \times$ change in $\mathrm{pH}$. Our results suggest that higher baseline $\mathrm{pH}$ leads to greater change in $\mathrm{pH}$ during storage, which together lead to decreased THC-glucuronide, THCCOOH-glucuronide, and total THCCOOH concentrations and increased THCCOOH concentrations. High inter-subject variability could also be caused by low analyte concentrations near the LOQ, the small number of $\mathrm{THCCOOH}$ positive low pools and the lack of commercially-available deuterated THC-glucuronide and THCCOOH-glucuronide internal standards at the time of this study. High inter-subject variability may confound stability findings.

It is unclear why 11-OH-THC appeared in 2 low and 3 high pools after one week at RT, as 11-OH-THC was suggested to be primarily an ether glucuronide that tends to be more stable than ester glucuronides. 11-OH-THC-glucuronide is present in urine, as evidenced by its increase following enzymatic or tandem alkaline-enzymatic hydrolysis [11, 29]; however, no commercial 11-OH-THC-glucuronide standard is available to evaluate its presence in this study. Further work is needed in order to fully characterize 11-OH-THC stability.

In summary, frozen storage provided optimal cannabinoid stability in urine, with THCglucuronide and $\mathrm{THCCOOH}$-glucuronide being stable for up to 6 months. Analysis should be conducted within 3 months if non-hydrolyzed THCCOOH or THCCOOH-glucuronide quantification is required. These data will aid those interpreting urinary cannabinoid results, as changes in concentration between repeat analyses can be explained with consideration of storage length.

\section{Supplementary Material}

Refer to Web version on PubMed Central for supplementary material. 


\section{Acknowledgments}

We acknowledge the contributions of the clinical staffs of the National Institute on Drug Abuse, Intramural Research Program, and Behavioral Pharmacology Research Unit and Clinical Research Unit, Johns Hopkins Bayview Medical Center, as well as Dr. David M. Schwope for protocol assistance, Dan Nichols and the staff at the Forensic Toxicology Drug Testing Laboratory in Fort Meade who provided urine creatinine data, the Graduate Partnership Program, NIH and the "Fondation Baxter et Alma Ricard". This research was funded by the Intramural Research Program, National Institute on Drug Abuse, NIH.

\section{References}

1. United Nations Office on Drugs and Crime (UNODC). [Accessed 21 September 2013] World Drug Report 2013. 2013. http://www.unodc.org/unodc/secured/wdr/wdr2013/ World_Drug_Report_2013.pdf.

2. Substance Abuse and Mental Health Services Administration. Results from the 2011 National Survey on Drug Use and Health: Summary of National Findings. NSDUH Series H-44. Rockville: U.S. Department of Health and Human Services; 2012. http://www.samhsa.gov/data/NSDUH/ 2012SummNatFindDetTables/NationalFindings/NSDUHresults2012.htm. [Accessed 21 September, 2013]

3. Drummer OH, Kourtis I, Beyer J, Tayler P, Boorman M, Gerostamoulos D. The prevalence of drugs in injured drivers. Forensic Sci Int. 2012; 215:14-17. [PubMed: 21377816]

4. Lacey, JH.; Kelley-Baker, T.; Furr-Holden, D.; Voas, RB.; Romano, E.; Ramirez, A.; Brainard, K.; Moore, C.; Torres, P.; Berning, A. [Accessed 21 September, 2013] 2007 National Roadside Survey of Alcohol and Drug Use by Drivers: Drug Results. National Highway Traffic Safety Administration Office of Behavioral Safety Research. 2009. http://www.nhtsa.gov/Driving+Safety/ Research+\&+Evaluation/ci.2007+National+Roadside+Survey+of+Alcohol+and+Drug+Use+by + Drivers.print

5. Mazur A, Lichti CF, Prather PL, Zielinska AK, Bratton SM, Gallus-Zawada A, Finel M, Miller GP, Radomińska-Pandya A, Moran JH. Characterization of Human Hepatic and Extrahepatic UDPGlucuronosyltransferase Enzymes Involved in the Metabolism of Classic Cannabinoids. Drug Metab Dispos. 2009; 37(7):1496-1504. [PubMed: 19339377]

6. Lowe R, Abraham T, Darwin W, Herning R, Cadet J, Huestis M. Extended Urinary delta 9 Tetrahydrocannabinol Excretion in Chronic Cannabis Users Precludes Use as a Biomarker of New Drug Exposure. Drug Alcohol Depen. 2009; 105(1-2):24-32.

7. Goodwin RS, Darwin WD, Chiang CN, Shih M, Li S-H, Huestis MA. Urinary Elimination of 11Nor-9-Carboxy-D9-tetrahydrocannabinol in Cannabis Users During Continuously Monitored Abstinence. J Anal Toxicol. 2008; 32(8):562-566. [PubMed: 19007504]

8. Smith ML, Barnes AJ, Huestis MA. Identifying New Cannabis Use with Urine CreatinineNormalized THCCOOH Concentrations and Time Intervals Between Specimen Collections. J Anal Toxicol. 2009; 33(4):185-189. [PubMed: 19470219]

9. Schwilke EW, Gullberg RG, Darwin WD, Chiang CN, Cadet JL, Gorelick DA, Pope HG, Huestis MA. Differentiating new cannabis use from residual urinary cannabinoid excretion in chronic, daily cannabis users. Addiction. 2011; 106(3):499-506. [PubMed: 21134021]

10. Daldrup, T.; Meininger, I. Berghaus, G.; Kruger, HP. Cannabis im Strassenverkehr. Stuttgart, Germany: Gustav Fischer Verlag; 1998.

11. Skopp G, Pötsch L, Ganßmann B, Mauden M, Richter B, Aderjan R, Mattern R. Freie und glucuronidierte Cannabinoide im Urin - Untersuchungen zur Einschätzung des Konsumverhaltens. Rechtsmedizin. 1999; 10(1):21-28.

12. Jung J, Kempf J, Mahler H, Weinmann W. Detection of Delta9-tetrahydrocannabinolic acid A in human urine and blood serum by LC-MS/MS. J Mass Spectrom. 2007; 42(3):354-360. [PubMed: 17219606]

13. Mareck U, Haenelt N, Geyer H, Guddat S, Kamber M, Brenneisen R, Thevis M, Schänzer W. Temporal indication of cannabis use by means of THC glucuronide determination. Drug Test Anal. 2009; 1(11-12):505-510. [PubMed: 20355165] 
14. Blanc JA, Manneh VA, Ernst R, Berger DE, de Keczer SA, Chase C, Centofanti JM, DeLizza AJ. Adsorption losses from urine-based cannabinoid calibrators during routine use. Clin Chem. 1993; 39:1705-1717. [PubMed: 8394791]

15. Roth KDW, Siegel NA, Johnson RW, Litauszki L, Salvati L Jr, Harrington CA, Wray LK. Investigation of the effects of solution composition and container material type on the loss of 11nor-delta-9-THC-9-carboxylic acid. J Anal Toxicol. 1996; 20:291-300. [PubMed: 8872237]

16. Stout PR, Horn CK, Lesser DR. Loss of THCCOOH from urine specimens stored in polypropylene and polyethylene containers at different temperatures. J Anal Toxicol. 2000; 24(7):567-571. [PubMed: 11043661]

17. Jamerson MH, McCue JJ, Klette KL. Urine $\mathrm{pH}$ container composition, and exposure time influence adsorptive loss of 11-nor-delta9-tetrahydrocannabinol-9-carboxylic acid. J Anal Toxicol. 2005; 29(7):627-631. [PubMed: 16419391]

18. Dugan S, Bogema S, Schwartz RW, Lappas NT. Stability of drugs of abuse in urine samples stored at-20 degrees. CJ Anal Toxicol. 1994; 18(7):391-396.

19. Golding Fraga S, Diaz-Flores Estevez J, Diaz Romero C. Stability of cannabinoids in urine in three storage temperatures. Ann Clin Lab Sci. 1998; 28(3):160-162. [PubMed: 9646857]

20. Romberg RW, Past MR. Reanalysis of forensic urine specimens containing benzoylecgonine and THC-COOH. J Forensic Sci. 1994; 39:479-485. [PubMed: 8195759]

21. Skopp G, Potsch L. Stability of 11-nor-delta(9)-carboxy-tetrahydrocannabinol glucuronide in plasma and urine assessed by liquid chromatography-tandem mass spectrometry. Clin Chem. 2002; 48(2):301-306. [PubMed: 11805011]

22. Skopp G, Potsch L. An investigation of the stability of free and glucuronidated 11-nor-delta-9tetrahydrocannabinol-9-carboxylic acid in authentic urine samples. J Ana Toxicol. 2004; 28:3540.

23. Felli M, Martello S, Chiarotti M. LC-MS-MS method for simultaneous determination of THCCOOH and THCCOOH-glucuronide in urine: Application to workplace confirmation tests. Forensic Sci Int. 2011; 204(1-3):67-73. [PubMed: 20627630]

24. Scheidweiler KB, Desrosiers NA, Huestis MA. Simultaneous quantification of free and glucuronidated cannabinoids in human urine by liquid chromatography tandem mass spectrometry. Clin Chim Acta. 2012; 413(23-24):1839-1847. [PubMed: 22771478]

25. Scheidweiler KB, Schwope DM, Karschner EL, Desrosiers NA, Gorelick DA, Huestis MA. In Vitro Stability of Free and Glucuronidated Cannabinoids in Blood and Plasma Following Controlled Smoked Cannabis. Clin Chem. 2013; 59:1108-1117. [PubMed: 23519966]

26. Faed EM. Properties of acyl glucuronides: implications for studies of the pharmacokinetics and metabolism of acidic drugs. Drug Metab Rev. 1984; 15(5-6):1213-1249. [PubMed: 6396057]

27. Shipkova M, Armstrong VW, Oellerich M, Wieland E. Acyl glucuronide drug metabolites: toxicological and analytical implications. Ther Drug Monit. 2003; 25(1):1-16. [PubMed: 12548138]

28. Robertson LW, Koh SW, Huff SR, Malhotra RK, Ghosh A. Microbiological oxidation of the pentyl side chain of cannabinoids. Experientia. 1978; 34(8):1020-1022. [PubMed: 700011]

29. Abraham TT, Lowe RH, Pirnay SO, Darwin WD, Huestis MA. Simultaneous GC-EI-MS determination of delta9-tetrahydrocannabinol: 11-hydroxy-delta9-tetrahydrocannabinol, and 11nor-9-carboxy-delta9-tetrahydrocannabinol in human urine following tandem enzyme-alkaline hydrolysis. J Anal Toxicol. 2007; 31(8):477-485. [PubMed: 17988462] 

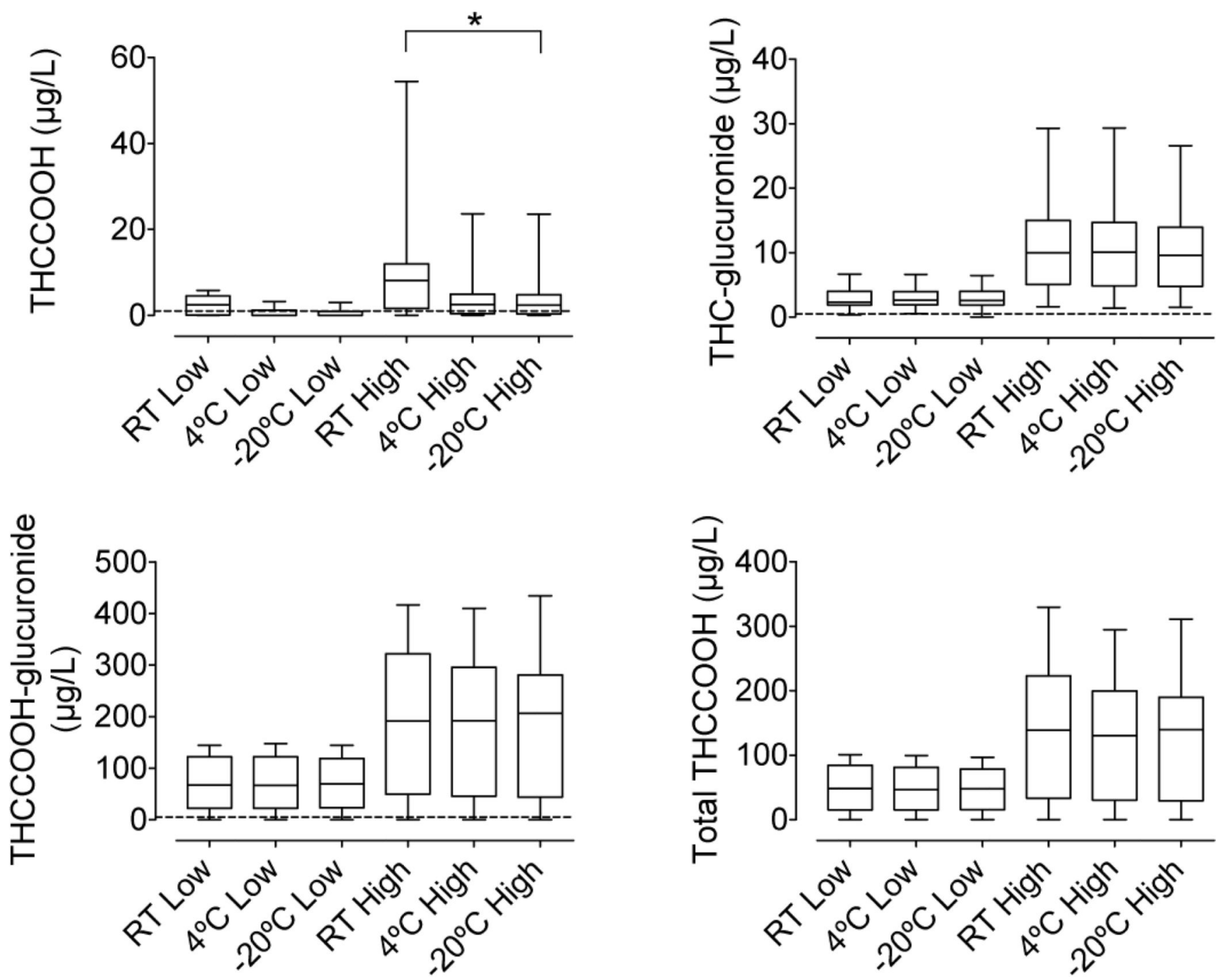

\section{Baseline Condition}

Fig 1.

Baseline concentrations in low and high cannabinoid urine pools prepared from samples collected after controlled cannabis smoking ( $\mathrm{n}=16$ participant pools)

Horizontal lines in boxes are medians and dashed lines are LOQs. All high pools were significantly higher than their temperature-matched low pool.

*Significant difference between storage temperatures 


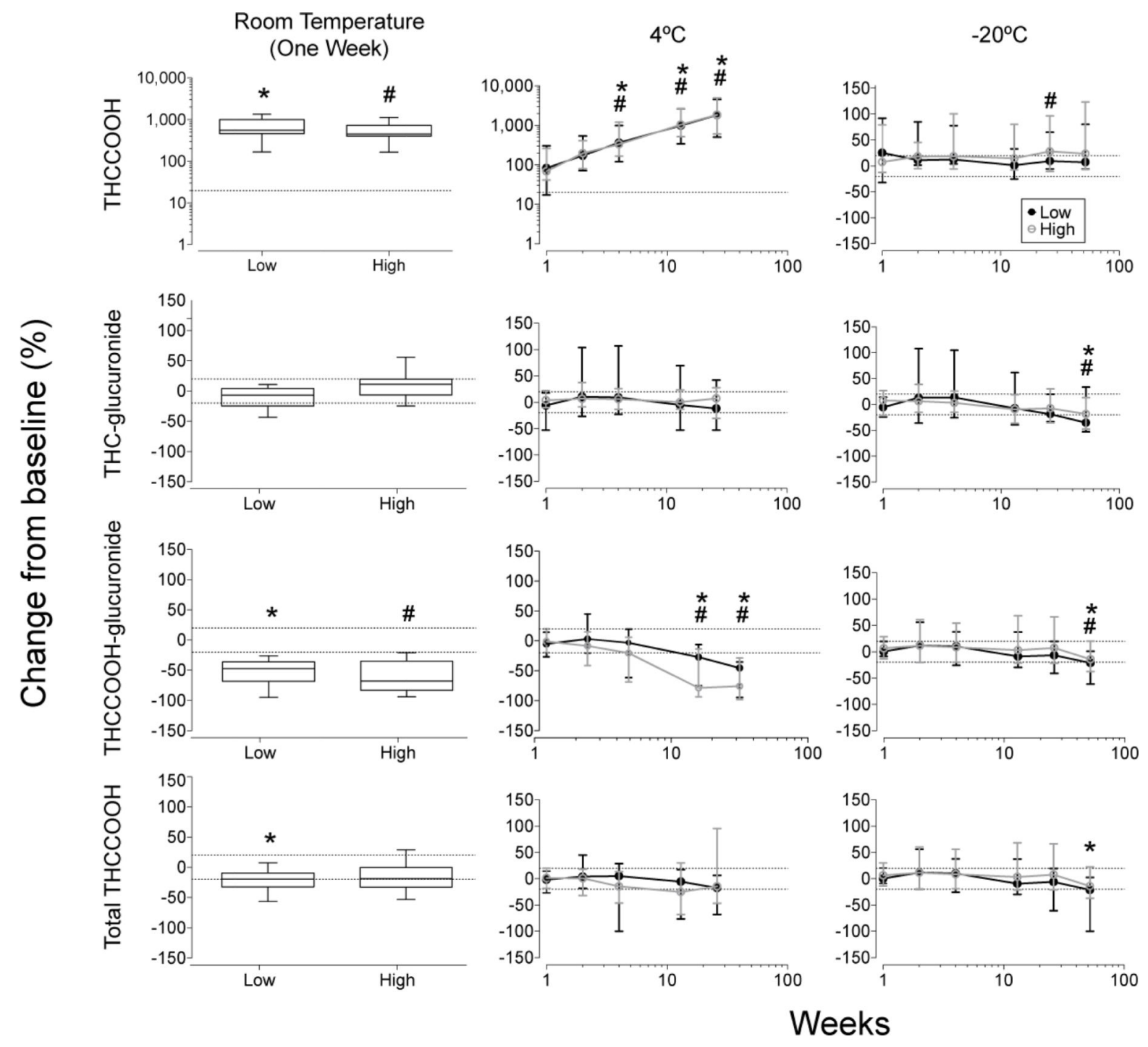

\begin{tabular}{|c|c|c|c|c|c|c|c|c|}
\hline \multirow{2}{*}{$\begin{array}{c}\text { Participants } \\
\text { included in } \\
\text { determination }\end{array}$} & \multicolumn{2}{|c|}{ THCCOOH } & \multicolumn{2}{|c|}{ THC-glucuronide } & \multicolumn{2}{l|}{$\begin{array}{c}\text { THCCOOH- } \\
\text { glucuronide }\end{array}$} & \multicolumn{2}{|c|}{ Total THCCOOH } \\
\cline { 2 - 10 } & Low & High & Low & High & Low & High & Low & High \\
\hline RT & 12 & 13 & 16 & 16 & 15 & 15 & 15 & 15 \\
\hline $4^{\circ} \mathrm{C}$ & 7 & 12 & 16 & 16 & 15 & 15 & 15 & 15 \\
\hline$-20^{\circ} \mathrm{C}$ & 5 & 12 & 15 & 16 & 15 & 15 & 15 & 15 \\
\hline
\end{tabular}

Fig 2.

Median (range) cannabinoid stability in baseline positive pools after 1 week at room temperature and up to 26 and 52 weeks at $4^{\circ} \mathrm{C}$ and $-20^{\circ} \mathrm{C}$, respectively, in low and high cannabinoid urine pools, collected after controlled cannabis smoking Significant differences from baseline for *low pool and \#high pool. Dashed lines represents $\pm 20 \%$ for $\mathrm{THCCOOH}$ (analyte with a deuterated internal standard) and $\pm 30 \%$ for THCglucuronide, THCCOOH-glucuronide and total THCCOOH (analytes without a matched deuterated internal standard) 

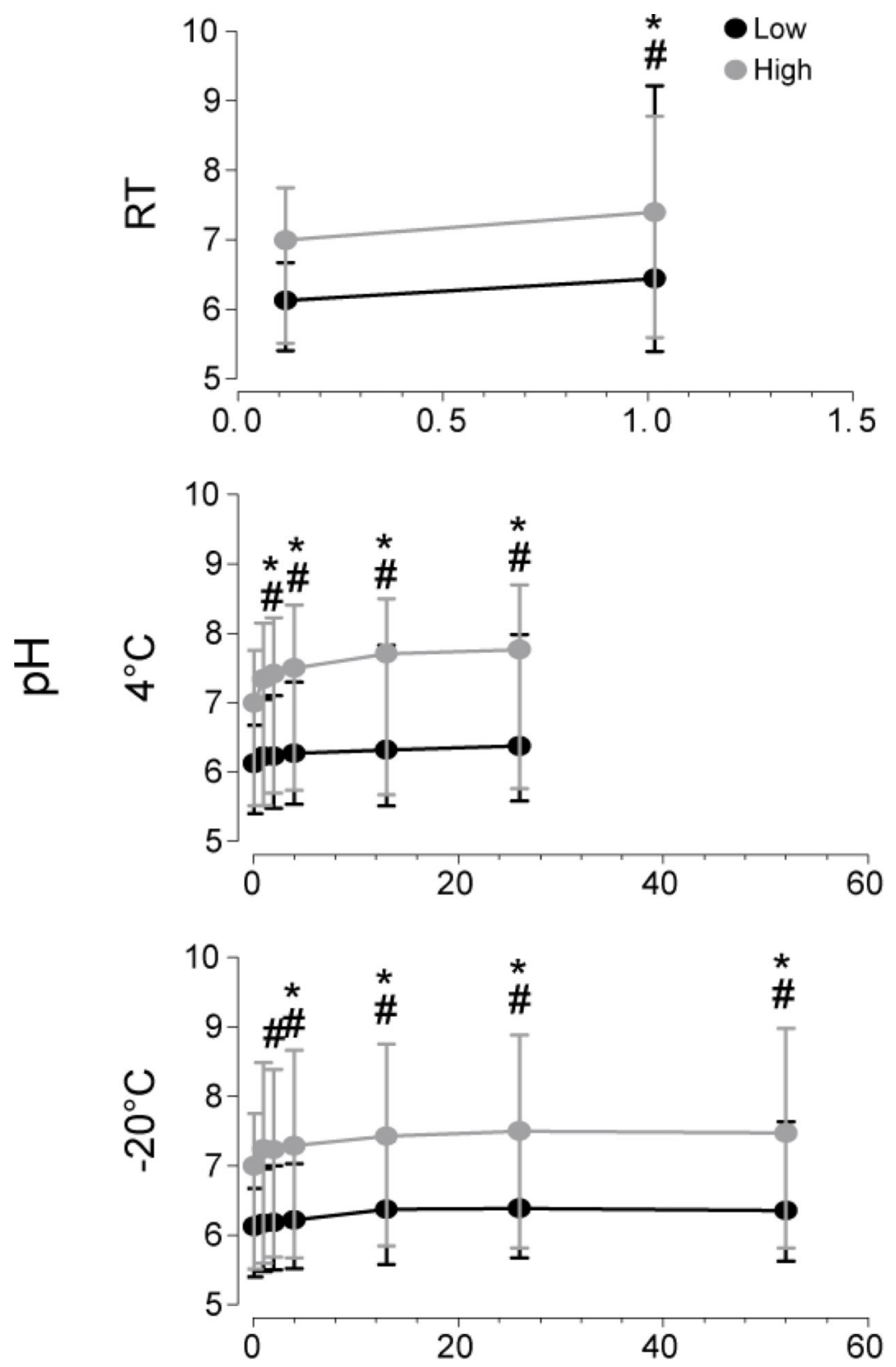

Weeks

Fig 3.

Median (range) urinary $\mathrm{pH}$ after 1 week at room temperature and up to 26 and 52 weeks at $4^{\circ} \mathrm{C}$ and $-20^{\circ} \mathrm{C}$, respectively, in low and high cannabinoid urine pools, collected after controlled cannabis smoking

Significant differences $(\mathrm{p}<0.05)$ from baseline for *low pool and \#high pool 


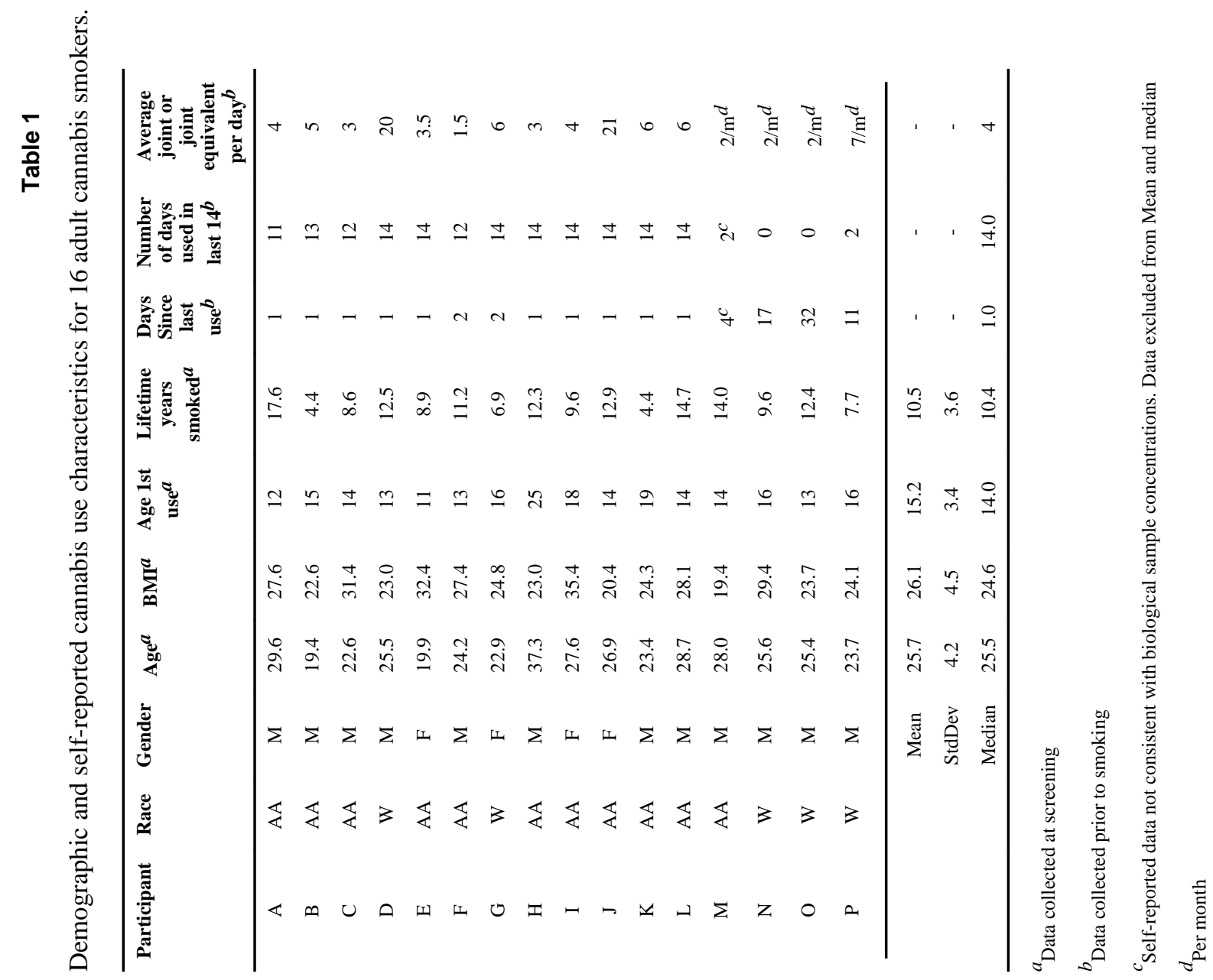


